\title{
Determination of Passive Failure Surface Geometry for Cohesionless Backfills
}

\author{
Behzad Soltanbeigi ${ }^{1}$ Adlen Altunbas ${ }^{2}$, Ahmet Talha Gezgin ${ }^{3}$, Ozer Cinicioglu ${ }^{*}$ \\ 1 Institute for Infrastructure and Environment, University of Edinburgh, Thomas Bayes Road, EH9 3JL Edinburgh, UK \\ 2 Department of Civil Engineering, Faculty of Engineering and Natural Sciences, Istanbul Medipol University, 34810 Beykoz, Istanbul, \\ Turkey \\ ${ }^{3}$ Department of Civil Engineering, Faculty of Engineering, Bogazici University, 34342 Bebek, Istanbul, Turkey \\ * Corresponding author, e-mail: ozer.cinicioglu@boun.edu.tr
}

Received: 28 April 2019, Accepted: 09 July 2020, Published online: 18 August 2020

\begin{abstract}
Correct determination of the passive failure surface geometry is necessary for the design of retaining structures. The conventional theories assume linear passive failure surfaces even though it is known that the actual failure surfaces are non-linear. Many researchers claimed the appropriateness of a hybrid curved-linear method. This approach estimates the curved section by a log-spiral function, which then connects to the backfill surface with the conventional linear assumption. The main drawback here is that the geometric properties of the hybrid mathematical function is not directly related to the mechanical properties of soils. Thus, this study attempts to provide a mechanical description for the assumed geometrical parameters. For this purpose, a series of $1 \mathrm{~g}$ small scale retaining wall model tests, simulating passive failure, are conducted on two different backfill soils. The relative density is varied in the model tests and the resultant peak friction angles of the backfills are calculated as functions of failure stress state and relative density using a well-known empirical equation. Transparent sidewalls allow for visualization of the failure surface evolution, which is obtained by capturing images and analysing then through Particle Image Velocimetry (PIV) technique. Subsequently, the quantified slip zones are fitted with the hybrid curved-linear approach. The relationships between the peak friction angle and the geometrical characteristics of the best-fit log-spiral and linear functions are investigated. Obtained results are used to propose a set of equations that allow the estimation of non-linear passive failure surfaces as function of peak friction angle.
\end{abstract}

\section{Keywords}

passive state, particle image velocimetry (piv), dilatancy, retaining wall, physical modelling

\section{Introduction}

Identification of the geometries of failure surfaces that emerge in backfills has critical importance in the analysis and design of retaining structures [1]. In the practice of geotechnical engineering, generally Coulomb [2] and Rankine [3] theories are used in design. Both theories are based on simplified assumptions regarding the geometry and orientation of the backfill failure surfaces. The common fundamental hypothesis of both theories is that the shear plane formed in the backfill at the ultimate state is a straight line, the inclination of which is only a function of the internal friction angle of the backfill. Several studies in literature investigated the evolution of lateral pressures and the formation of shear bands in retained backfills. Some of these used experiments [4-11] whereas the others preferred numerical methods [12-18].
One common outcome of all studies on the subject is that effective strength parameters (cohesion, soil friction angle, or soil-wall interface friction angle) control the magnitude of passive pressure [7]. This is expected since the problem involves a limit state problem. Additionally, several researchers noticed other influencing factors that control the magnitude of lateral thrust, such as: backfill density [19], pressure level [19] and dilation angle of backfill soil [19-21].

On the other hand, the results of all these studies suggest that the geometries of slip surfaces that emerged in retained backfills at failure are nonlinear. In the literature, factors affecting the geometries of passive failure surfaces are as following: internal friction angle $[22,23]$, interface friction angle [23], backfill density [19]. 
Regarding the mathematical form of the nonlinear failure surface, researchers generally suggested a composite form including both linear and logarithmic spiral sections $[7,12,23,24]$.

Liu et al. [25] suggested a modified method to obtain the failure surface geometry and earth pressure coefficient for passive state of failure. The proposed approach is based on the logarithmic spiral method developed by Terzaghi [24]. To find the corresponding angle of the logarithmic spiral (which determines the characteristics of the spiral), a mathematical solution is used (i.e. using the bisection method for root-finding). Additionally, for a backfill without surface inclination, it is assumed that linear portion of the failure surface meets the backfill surface with an angle of $\pi / 4-\phi^{\prime} / 2$ (i.e. Rankine zone). Successively, the proposed method is verified by using FEM numerical approach. Overall, it is shown that obtained results from the proposed method are in agreement with those of FEM simulations.

$\mathrm{Xu}$ et al. [26] proposed an analytical approach to estimate the stress state within a retained backfill. In this method, a log-spiral failure surface is assumed, which is discretized into dices. Then, the forces acting on each dice (depending on its location, within or at the boundary of the log-spiral region), allowing observation of local internal forces distribution. The inter-dice normal and shear forces are obtained through considering integration of the relationships gained by satisfying the force and momentum equilibrium. This method is verified by FEM simulations, and it is pointed out that the normal and shear stresses obtained from both methods are similar in most parts of the backfill (except near the wall boundary).

Unfortunately, none of these studies offered a practical guidance by which the geometrical characteristics of the logarithmic spiral failure surface can be obtained. All suggestions were left at the level of identifying the suitability of using logarithmic spiral form as a good fit to the passive failure surfaces.

This study attempts to address this deficiency by linking the geometrical characteristics of logarithmic spiral to the properties of backfill soils. From mentioned previous studies, it is deduced that peak friction angle can be referred as a global parameter that encompasses the influences of other affecting factors. The peak friction angle $\left(\phi_{p}^{\prime}\right)$ is a combined outcome of critical state friction angle $\left(\phi_{c}^{\prime}\right)$ and peak dilatancy angle $\left(\psi_{p}\right)$ [27-31]. As $\psi_{p}$ is dependent on the collective influences of backfill density and pressure level [31], and $\phi_{c}^{\prime}$ is a soil constant, $\phi_{p}^{\prime}$ embodies the joint influences of all influential parameters listed above. That is why the goal of this study is to devise a method which mathematically defines logarithmic spirals to fit passive failure surfaces as functions of backfill peak friction angles.

For this purpose, small scale retaining wall model tests are conducted with two different sand types. This study is limited to the investigation of vertical retaining systems that translate horizontally under plane strain conditions. Wall rotation and different wall geometries are out of the scope of this study as this is the first attempt at linking the geometrical characteristics of logarithmic spiral functions to measurable soil properties. Well-known empirical equations from literature are used to calculate the peak friction angles of model backfills as functions of density and failure stress state. PIV method is employed to visualize and determine the geometries of failure surfaces. As a result, it became feasible to investigate the influence of $\phi_{p}^{\prime}$ on the geometrical characteristics of failure surfaces. Finally, an empirical method, by which the geometries of passive failure surfaces can be accurately predicted, is presented.

\section{The retaining wall model}

To investigate geometries of failure surfaces, $1 \mathrm{~g}$ small scale retaining wall model tests are conducted. In each model test, backfill soil is prepared at a different relative density $\left(I_{D}\right)$. Under $1 \mathrm{~g}$ conditions, the magnitude of backfill soil's $\phi_{p}^{\prime}$ directly changes with the changes in relative density. This way, it becomes possible to monitor the influence of $\phi_{p}{ }^{\prime}$ on failure surface geometry. Physical model set-up consists of a testing box, a model retaining wall that is capable of only translating laterally, a sand pluviation system, a storage tank, a crane, and a data acquisition system, as shown in Fig. 1(a). The testing box is, $140 \mathrm{~cm}$ in length, $60 \mathrm{~cm}$ in depth, and $50 \mathrm{~cm}$ in width, as illustrated in Fig. 1(b) and Fig 1(c). Sides of the box are made of $20 \mathrm{~mm}$ thick Plexiglas allowing the observation and monitoring of soil deformations. To maintain plane-strain conditions at all stages of the test, it is necessary to prevent lateral deflections of Plexiglas side walls. For this purpose, model frame is equipped with metal braces supporting the Plexiglas side walls (Fig. 1(a)). Though the braces obstruct a small portion of the view when photographs of the tests are captured, this in no way hinders the identification of the failure surface geometry. Through the transparent side walls, photographic images of the backfill at different stages of wall deformation can be captured for examination. Obtained images are analyzed using PIV method, which led to visualized passive failure surfaces [32-36]. The model retaining wall is an 
aluminium plate with rectangular cross-section. The height and width of the model wall are $35 \mathrm{~cm}$ and $50 \mathrm{~cm}$, respectively. To minimize the adverse effects of the rigid boundary at the bottom, the moving plate that simulates the vertical retaining wall is located $15 \mathrm{~cm}$ above the bottom of the test box. An electrical motor-actuator system drives the model wall laterally either towards or away from the retained backfill. The displacements of the wall are measured by an electronic ruler. Motor displacement steps are used to validate the measurements of the electronic ruler. Fig. 1(d) shows five sensitive miniature pressure transducers mounted along the vertical axis of the model wall for observing the variations of lateral earth pressures along the face of the wall. Density cans are buried in the backfill during model preparation stage at the further end of the box away from the model wall. This way these cans do not interfere with the evolution of failure surfaces and they provide the means to measure backfill density after the completion of model tests. Variations of vertical stresses within the backfill are calculated using the measurements of the density cans. To verify vertical stress calculations, two miniature pressure transducers are buried in the backfill during model preparation stage of each test (Fig. 1(b) and Fig. 1(c)). A multi-channel data logger system is used for collecting data. Data logger is capable of handling an aggregate data collection rate of $400 \mathrm{kHz}$, with a maximum per channel sample rate of up to $500 \mathrm{~Hz}$ which is more than sufficient considering the velocity of model wall movement.

\section{Calculation of peak friction angle of backfill soils}

The goal of this study is to link the geometrical characteristics of failure surfaces to backfill soil's $\phi_{p}^{\prime}$. Therefore, it is necessary to know the magnitude of $\phi_{p}^{\prime}$ once the backfill is prepared. This is not an easy task as $\phi_{p}^{\prime}$ varies with pressure, density, stress path and loading conditions. It is not possible to prepare equivalent samples of backfill soils for strength testing. Even though the sample is prepared with the same relative density as the model, changes in the symmetry conditions (axisymmetric versus plane strain), stress state or stress path will result in the deviation of the measured values from the model values. Therefore, an alternative method is necessary to obtain the values of $\phi_{p}^{\prime}$ that prevail in the backfill. For this purpose, well-known empirical equations, available in literature, are used to determine $\phi_{p}^{\prime}$. First of these equations are given in Eq. (1) and relate $\phi_{p}^{\prime}$ to $\phi_{c}^{\prime}$ and $\psi_{p}^{\prime}$ of the backfill soil.

$\phi_{p}{ }^{\prime}=\phi_{c}{ }^{\prime}+r \psi_{p}$

Here, $r$ is an empirical line-fitting parameter. $\psi_{p}$ is also referred as the maximum rate of dilatancy and it is measured at the instance of peak failure. The relationship given in Eq. (1) was first described by Bishop [27] and later formulated by Bolton [28] in its final form. The magnitude of $r$ is dependent on sample symmetry conditions. Second empirical equation (Eq. (2)) allows the calculation of $\psi_{p}$ as a function of backfill relative density $\left(I_{D}\right)$ and mean effective stress at failure $\left(p_{f}^{\prime}\right)$ [28]:

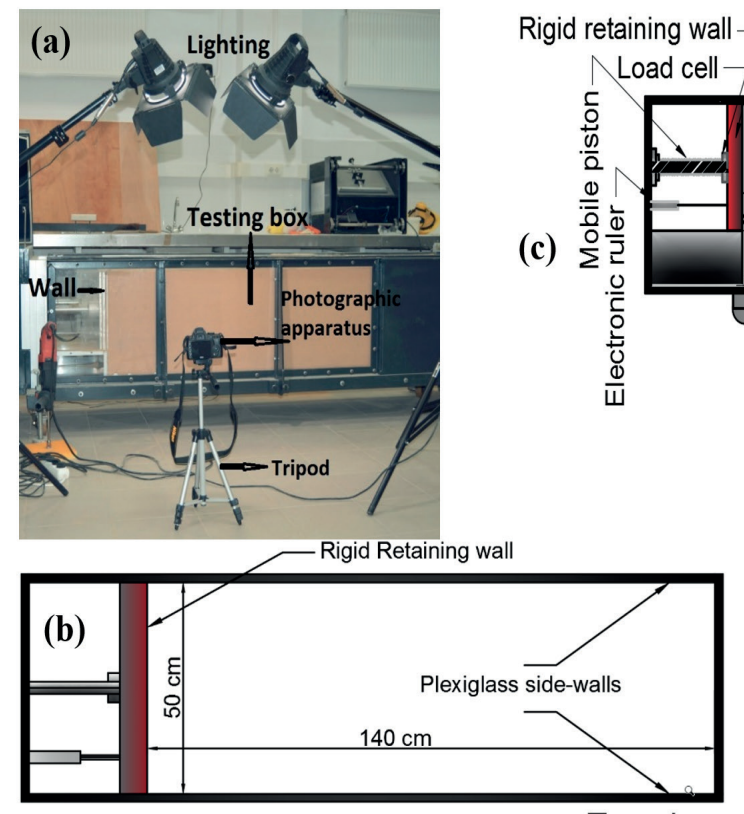

Top view

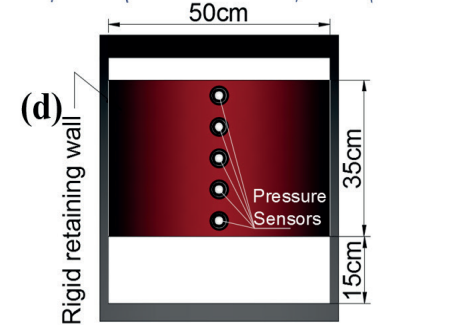

Fig. 1 Retaining wall model set-up a) actual photograph b) schematic vertical cross-section c) schematic plan view d) location of sensors on the wall 
$\psi_{p}=\frac{A_{\psi}}{r} I_{R}=\frac{A_{\psi}}{r}\left[I_{D}\left(Q-\ln \frac{100 p_{f}{ }^{\prime}}{p_{a}}\right)-R\right]$

Here, $Q, R$ and $r$ are empirical line-fitting parameters that depend on inherent soil characteristics and $p_{a}$ is the atmospheric pressure. The values of $Q$ and $R$ for the testing sand are obtained by triaxial testing. Chakraborty and Salgado [30] suggested that the value of the parameter $Q$ depends on the magnitude of initial confining stress $\left(p_{i}^{\prime}\right)$ of the soil. The results of the triaxial tests conducted for this study supported the findings of Chakraborty and Salgado [30]. Following Chakraborty and Salgado [30], the magnitude of $Q$ can be calculated using Eq. (3):

$Q=\eta+\beta \ln p_{i}^{\prime}$.

Here, $\beta$ and $\eta$ are soil-specific empirical line-fitting parameters. Chakraborty and Salgado [30] showed that Eq. (3) is suitable for stresses that range from low to intermediate. The $p_{i}^{\prime}$ values of the triaxial tests of this study range from $25 \mathrm{kPa}$ to $500 \mathrm{kPa}$ and the soil specific values of the parameters $\beta, \eta$, and $R$ are obtained for the two soils used. Values of these parameters for both soils used in this study are given in Table 1 . It is known that $\psi_{p}$ is independent of sample symmetry conditions [28, 37]. Therefore, at the same stress state, identical $\psi_{p}$ values are measured in plane strain and triaxial tests. Consequently, it is possible to calculate $\psi_{p}$ of the model backfill using the line-fitting parameters obtained by triaxial testing.

On the other hand, it is known that the values of $\phi_{p}{ }^{\prime}$ measured under axisymmetric and plane strain conditions differ [37-39]. According to Schanz and Vermeer [37], this difference is caused by the dependence of $\phi_{p}^{\prime}$ on density and stress path. Since the stress path under axisymmetric and plane strain conditions diverge, measured $\phi_{p}{ }^{\prime}$ values also differ. That is why, $\phi_{p}^{\prime}$ values are calculated with Eq. (1), which uses line-fitting parameters suitable for axisymmetric conditions, are converted into $\phi_{p}{ }^{\prime}$ values that are relevant for plane strain conditions. This is achieved using a method proposed by Hanna [39]. The $r$ values relevant for axisymmetric and plane strain conditions for both backfill soils are given in Tables 1 and 2. Inserting the values of $\psi_{p}$ (calculated using Eq. (2)), $\phi_{c}^{\prime}$ of the soil and $r$ value (specific to plane strain condition) into Eq. (1), the magnitude of plane strain $\phi_{p}^{\prime}$ can be calculated. Once the value of $\phi_{p}^{\prime}$ is obtained for each model test, it becomes possible to investigate the influence of $\phi_{p}^{\prime}$ on failure surface geometry.
Apparently, Eq. (2) requires the input of $p_{f}^{\prime}$. The magnitude of $p_{f}^{\prime}$ is measured at the instance of failure using the pressure transducers. Available transducers measure the normal stress in the vertical direction and in the horizontal direction normal to the wall. As a result, the normal stress in the orthogonal horizontal direction must be calculated. The model box conforms to plane strain conditions. Therefore, at-rest conditions prevail in the direction of the normal to the sidewall. Accordingly, normal stresses in the direction of the sidewall normal are assumed to be equal to the measured lateral earth pressures before the occurrence of any deformation.

\section{Backfill properties and sample preparation}

Two different sand types are used in this study; these are Akpinar $\left(\mathrm{S}_{1}\right)$ and Sile $\left(\mathrm{S}_{2}\right)$ sands which are obtained from different regions around Istanbul. $\mathrm{S}_{1}$ and $\mathrm{S}_{2}$ sands are poorly graded according to United Soil Classification System (USCS), see Fig. 2.

A summary of the physical characteristics of the sands are given in Table 1. Particle shape characteristics are quantified based on the grain shape charts proposed by Cho et al. [40].

Direct shear tests are conducted to measure the interface friction angle between the model wall and the backfill sand. Measured backfill model-wall interface friction angles vary between $18^{\circ}$ (loosest) and $24^{\circ}$ (densest) for $\mathrm{S}_{1}$ and $\mathrm{S}_{2}$ sands.

It must be noted that in the current study the model wall material is the same in all tests. The underlying reason for this choice is that in practice the interface friction can vary within a limited range for sand backfills. For interface problems in sands, the roughness of a surface is typically quantified by the normalized roughness ratio which is the ratio of maximum roughness to mean grain diameter $\left(D_{50}\right)$ [41]. Maximum roughness is defined as the maxi-

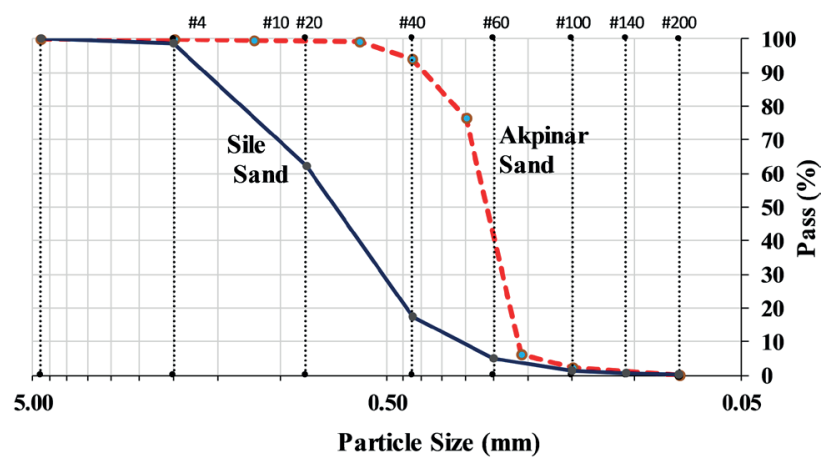

Fig. 2 Grain size distribution curve for Akpinar $\left(\mathrm{S}_{1}\right)$ and Sile $\left(\mathrm{S}_{2}\right)$ sands 
Table 1 Mechanical Properties of Akpinar and Sile Sands

\begin{tabular}{lcc}
\hline Property & Akpinar Sand $\left(\mathrm{S}_{1}\right)$ & Sile Sand $\left(\mathrm{S}_{2}\right)$ \\
\hline Classification & $\begin{array}{c}\text { Poorly Graded } \\
(\mathrm{SP})\end{array}$ & $\begin{array}{c}\text { Poorly Graded } \\
(\mathrm{SP})\end{array}$ \\
$\begin{array}{l}\text { Max. void ratio, }\left(e_{\max }\right) \\
\text { (ASTM D-4253) }\end{array}$ & 0.87 & 0.78 \\
$\begin{array}{l}\text { Min. void ratio, }\left(e_{\min }\right) \\
\text { (ASTM D-4254) }\end{array}$ & 0.58 & 0.52 \\
$\begin{array}{l}\text { Uniformity coefficient, }\left(C_{u}\right) \\
\text { Coefficient of gradation, }\left(C_{c}\right)\end{array}$ & 1.23 & 2.8 \\
$\begin{array}{l}\text { Specific gravity, }\left(G_{s}\right) \\
\text { Average sphericity, }\left(S_{\text {ave }}\right)\end{array}$ & 0.97 & 1.12 \\
$\begin{array}{l}\text { Average roundness, }\left(R_{\text {ave }}\right) \\
\text { Dilatancy effect on friction for } \\
\text { axisymmetric conditions, }\left(r_{t x}\right)\end{array}$ & 2.63 & 2.61 \\
$\begin{array}{l}\text { Dilatancy effect on friction for } \\
\text { plane strain conditions }\left(r_{p s}\right)\end{array}$ & 0.70 & 0.55 \\
$\begin{array}{l}\text { Critical state friction angle, } \\
\left(\phi_{c}^{\prime}\left({ }^{\circ}\right)\right)\end{array}$ & 0.50 & 0.76 \\
$\begin{array}{l}\text { Bolton coefficients } Q \\
\text { Bolton coefficients } R\end{array}$ & 33.0 & 0.55 \\
\hline
\end{tabular}

mum vertical distance between a peak and a trough of the surface over a length equal to the mean grain diameter. However, following the definition of roughness, in practice it is impossible to have retaining wall surfaces that are perfectly smooth/rough. Accordingly, considering the interfaces between sand-sized grains and retaining structures (constructed with modern tools and materials), expected interface friction angle is unlikely to exceed the range of variation that was proposed by Terzaghi [24]. He suggested that the magnitude of interface friction angle varies between one-third and two-thirds of for practical applications. The obtained interface friction angles for this study are also within this range.

Low friction transparent high-density polyethylene sheets are applied on the plexiglass side walls to satisfy plane-strain conditions. In order to investigate the influence of soil friction angle on the geometry of passive failure surface, tests are conducted with backfills that have different peak friction angles. This is achieved by preparing the backfill soils with different relative densities.

Model backfills are prepared by dry-pluviation. Pluviation height is adjusted to achieve different relative densities. Whenever the target relative density cannot be reached by pluviation only, a hand-held electric compactor is used to compact the backfill in layers. Cinicioglu and Abadkon [31] showed that neither $\psi_{p}$ nor $\phi_{p}^{\prime}$ are influenced by overconsolidation ratio (OCR). As a result, Eq. (1) and
Eq. (2) can still be used to calculate the magnitude of $\phi_{p}^{\prime}$ for the model backfill. As soon as a test is completed, density cans buried in the backfill are extracted and weighed. The results are used for calculating backfill relative density and to check backfill homogeneity. Insignificantly small variations in vertical stresses under $1 \mathrm{~g}$ conditions justify the assumption of uniform $\phi_{p}^{\prime}$ for the whole model. Passive failure of backfill is simulated by horizontally translating the model wall toward the backfill. Since, the tests are conducted with dry sand, there is no rate effect influencing soil response. Thus, based on the image-capturing rate of the camera, the translation speed of the model wall is adjusted $(0.5 \mathrm{~mm} / \mathrm{s})$, which ensures the image quality level (i.e. resolution).

\section{Failure surface geometry by PIV}

In this study, PIV is used for monitoring the evolution of the backfill deformation caused by the translation of the model wall. GeoPIV-RG, a MATLAB based PIV software, specifically utilized for geotechnical applications, is used for the analyses of the images captured during the tests. Detailed information regarding GeoPIV-RG algorithms can be found in Stanier et al. [42]. PIV method is a popular approach to detect the deformations in soil medium [43].

The utilized camera can capture four images per second. This rate is enough for monitoring the quasi-static deformations of the model backfill. In all tests, the camera is placed at a fixed distance from the wall and the model is illuminated using special projectors to ensure the highest image quality.

Cumulative shear strain maps for different stages of the tests are obtained from the GeoPIV-RG analyses. Strain maps, corresponding to the instance of passive failure, for each test are color-coded based on strain magnitude. The high visual contrast achieved in these images makes it easier to distinguish the passive failure surfaces. In order to quantify the geometries of discerned failure surfaces, a coordinate system is established. The vertical axis of the coordinate system is coincident with the initial position of the model wall and the origin is located at the bottom of the wall. Using this coordinate system, coordinates of the points along the failure surface that correspond to outer edge of failure surface are digitized. All coordinate measurements are done with respect to the position of the wall before any displacement. In order to achieve unit-independent quantification, measured coordinates of the failure surface are normalized by height of the model wall $\left(H_{w}\right)$. 
The presence of the braces that are necessary for satisfying plane strain conditions partially blocks the view of the failure surface geometry. However, braces are essential to prevent the bulging of plexiglass during soil deformation. However, failure surface geometry is clearly discernible, and the obstructed portion can be easily interpolated as observed in Fig. 3.

\section{Determination of failure surface geometry}

Based on the results of PIV analyses, geometries of failure surfaces are determined in all model tests for both sand types, as shown in Fig. 4. Evident from all results, geometries of all passive slip planes are nonlinear and link the toe of the rigid retaining wall to the surface of the cohesionless backfill. It is clear that the magnitude of peak friction angle, which is obtained through peak dilatancy angle, influences the shapes of failure surfaces. Additionally, the failure surfaces emerge at the ground level in the order of their respective $\phi_{p}^{\prime}$ magnitudes. In other words, higher magnitudes of $\phi_{p}^{\prime}$ results in greater $B_{f}$ values.

\section{Prediction of slip plane geometry}

As explained in the introduction section, several researchers suggested the suitability of using logarithmic spiral as the mathematical function to define the shapes of passive failure

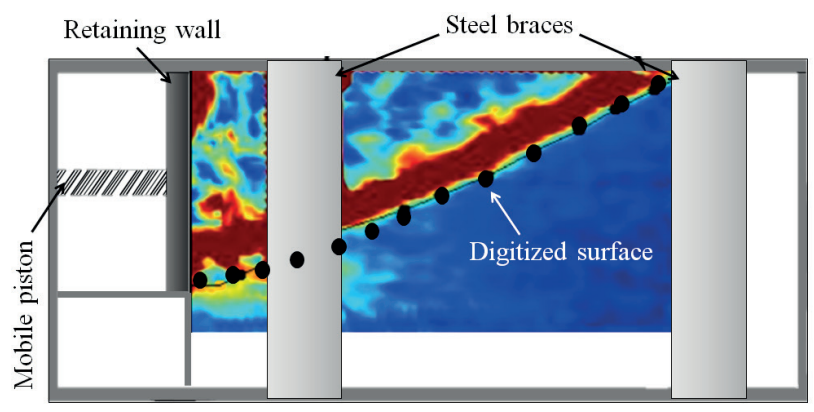

Fig. 3 Determination of the failure surface geometry as plotted on the cumulative shear strain map (for $\mathrm{S}_{2}$ sand with)
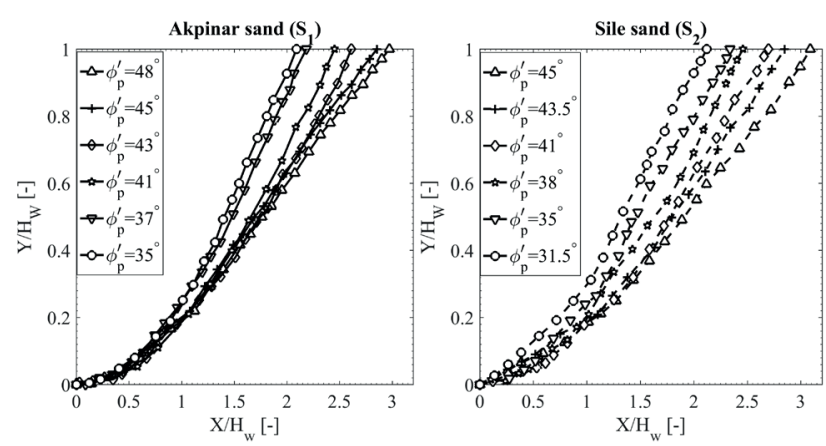

Fig. 4 Geometries of passive failure surfaces obtained from PIV analyses (for backfills with various peak friction angles) surfaces in cohesionless soils [7, 12, 23, 24]. However, the current approach to define the log-spiral failure surface is based on predefined assumptions, which then follows a trial and error procedure. Accordingly, an ideal approach, which provides the geometrical characteristics of logarithmic spiral failure surfaces as a function of soil properties is still lacking in the literature. Therefore, this study attempts to cancel the necessity for the prevailing assumptions, which would enhance the accuracy of passive failure surface predictions. To this end, the geometrical characteristics of the slip plane are correlated with the backfill peak friction angle. This is achieved by fitting logarithmic spirals to experimentally determined passive failure surfaces and then investigating the correlation between backfill $\phi_{p}{ }^{\prime}$ and the geometrical characteristics of the logarithmic spirals that best fit the determined failure surfaces.

Experimentally observed passive failure surfaces can be divided into spiral and linear sections. The linear section is an extension of the spiral part (Fig. 5). Assuming that the spiral portions of passive failure surfaces have logarithmic spiral forms, Terzaghi et al. [44] suggested that the log-spiral that yields the smallest total passive resistance corresponds to the actual passive failure surface. To find this failure plane, Terzaghi et al. [44] explained the necessary steps and assumptions as given below:

For cohesionless soils at passive limit state, a force equilibrium must exist between PP (resultant of the normal and frictional components of the passive earth pressure), the weight of the area $A B C D$ (see Fig. 5) and the frictional resistance due to the weight. It is also assumed that PP acts at lower third of $A D$ (i.e. wall height). Additionally, following assumptions are made to obtain the composite passive failure surface (linear and curved portions):

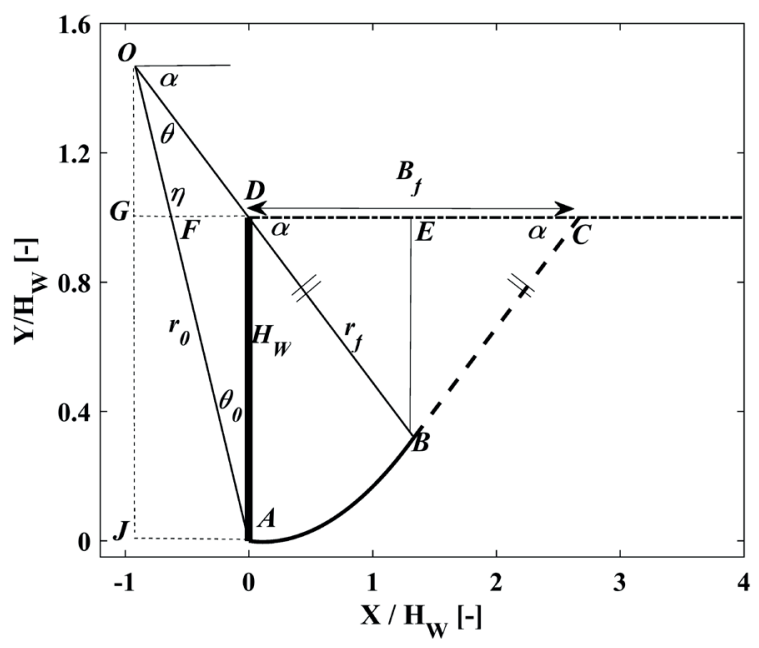

Fig. 5 Schematic interpretation of the log-spiral theory 
The linear part $(B C)$ makes $\pi / 4^{-} \phi^{\prime} / 2$ with the horizontal surface of the backfill. The curved section is tangent to the linear part at $\mathrm{B}$, and the center of spiral passes through $D B$, which also makes $\pi / 4-\phi^{\prime} / 2$ with the horizontal surface of the backfill (an isosceles triangle is formed above $A B D$ curved wedge).

The curved lower part of failure surface $(A B)$ is an arc of a logarithmic spiral, defined as:

$$
r=r_{0} e^{\theta \tan \phi^{\prime}},
$$

where, $r_{0}$ is the initial radius of the spiral $(O A), \theta$ is the spiral angle (angle between $r$ and $r_{0}$ ), $O$ is the pole of the spiral located along the $B D$ line (can be out of the zone defined by the limiting points $B$ and $D$ ) (Fig. 5).

To compute PP, the sliding surface $A B C$ composed of spiral $(A B)$ and linear $(B C)$ sections is defined. This is done by varying the position of the pole of the spiral along the line $B D$ (referred as the s-line). This iterative process is continued until the desired failure surface that yields the smallest total passive resistance is obtained. However, this proposed graphical solution needs considerable time and effort. On the other hand, accuracies of the failure surfaces obtained by considering the abovementioned assumptions, have never been validated by model tests. Accordingly, in the next section, attempt has been made to evaluate the applicability of the log-spiral method for defining slip surface geometries using model test results. Following, possible relationships between the defining geometrical characteristics of the experimentally obtained best-fit spiral functions and $\phi_{p}{ }^{\prime}$ will be examined.

\subsection{Necessary steps for plotting the best-fit log-spiral failure surface}

Fitting the experimentally obtained failure surfaces with log-spirals requires the identification of two unknowns, $\alpha$ and $\theta_{0}$. Here, $\alpha$ is the angle that forms between the line $B C$ and the horizontal, and $\theta_{0}$ is the angle that forms between the line $O A$ and the vertical, as shown in Fig. 5. One of the main assumptions for the determination of the log-spiral is that the final radius of the log-spiral $(O B)$ must make an angle equal to $\alpha$ with the free surface of the backfill (passing through top of the wall). The origin of $\log$-spiral $O$ is located on $O B$ line as well. PIV analyses of the model tests visually reveal the value of $\alpha$. Since $\alpha$ is obtained experimentally, iteration is necessary only for determining the value of $\theta_{0}$, which determines the location of $O$ (Point $O$ lies at the intersection of the extension of the line $\mathrm{BD}$ and the line that starts at point A making the angle $\theta_{0}$ with the vertical). Each iteration requires several steps to plot the log spiral and the linear portion. This is performed by a script in MATLAB.

Experimentally obtaining the value of $\alpha$ and assuming a value for $\theta_{0}$, the value of $\theta$ and $\eta$ are obtained as follows:

$\theta=90^{\circ}-\theta_{0}-\alpha$,

$\eta=180^{\circ}-\alpha-\theta$.

Then, it is possible to obtain lengths of $F D, O D, O F$, $G F, O G$, and $F A$ using the geometry of the problem given in Fig. 5. Accordingly, length of $r_{0}$ is obtained as:

$r_{0}=O F+F A$.

Inserting $O F$ and $F A$ into Eq. (7):

$r_{0}=H_{W} \tan \left(\theta_{0}\right)\left(\frac{\sin (\alpha)}{\sin (\theta)}+\frac{1}{\cos \left(\theta_{0}\right)}\right)$.

Location of $O$ defined by $O J$ and $J A$, which is obtained using $r_{0}$ and $\theta_{0}$ :

$O J=r_{0} \cos \left(\theta_{0}\right)$,

$J A=r_{0} \sin \left(\theta_{0}\right)$.

Having $r_{0}$ and $O$, it is now possible to determine the log-spiral part of the failure surface. This requires replacing $\theta$ by $i$ values $(0<i<\theta)$. Every gradual increase in $i$ results in a new radius for the spiral $\left(r_{n}\right)$ and ultimately when $i=\theta, r_{n}$ will be equal to $r_{f}$ Coordinates for the end point of $r_{n}$ is calculated through:

$$
\begin{aligned}
& Y_{i}=r_{0} \cos \left(\theta_{0}\right)-\left(r_{n} \cos \left(\theta_{0}+i\right)\right), \\
& X_{i}=r_{n} \sin \left(\theta_{0}+i\right)-G D,
\end{aligned}
$$

Where,

$G D=H_{W} \tan \left(\theta_{0}\right)\left(\frac{\sin (\alpha) \sin \left(\theta_{0}\right)}{\sin (\theta)}+1\right)$.

Having the coordinates of $B\left(X_{f}, Y_{f}\right)$, it is possible to plot the linear portion as well. Fig. 6 visually explains the influence of $\theta_{0}$ on the resulting failure surfaces.

\section{Results}

The failure surfaces, determined experimentally through PIV analyses, are fitted with log-spiral functions. The results are presented in Fig. 7 and Fig. 8 for model tests with $S_{1}$ and $\mathrm{S}_{2}$ sands, respectively. The magnitudes of backfill $\phi_{p}{ }^{\prime}$ and $\psi_{p}$ are reported in the legends of each figure. 


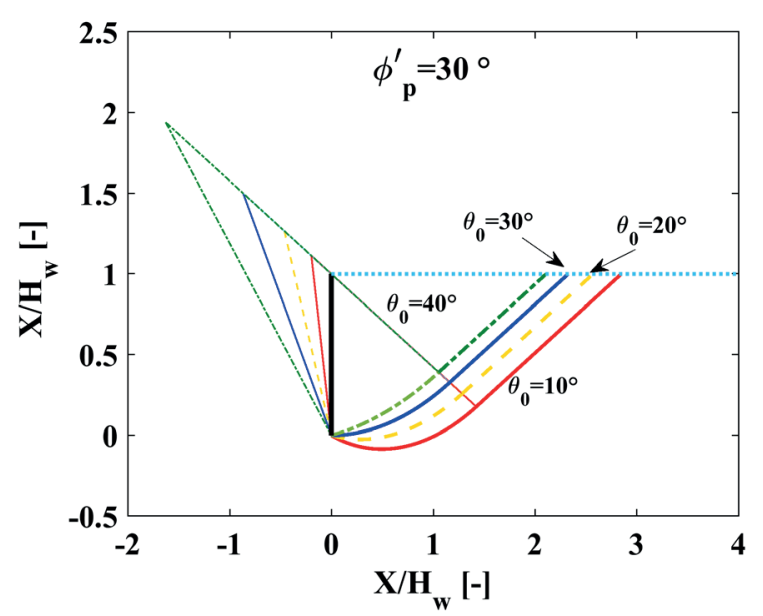

Fig. 6 Influence of the unknown parameter $\theta_{0}$ on the resulting failure surface (for a backfill with $\phi_{p}{ }^{\prime}=30^{\circ}$ )
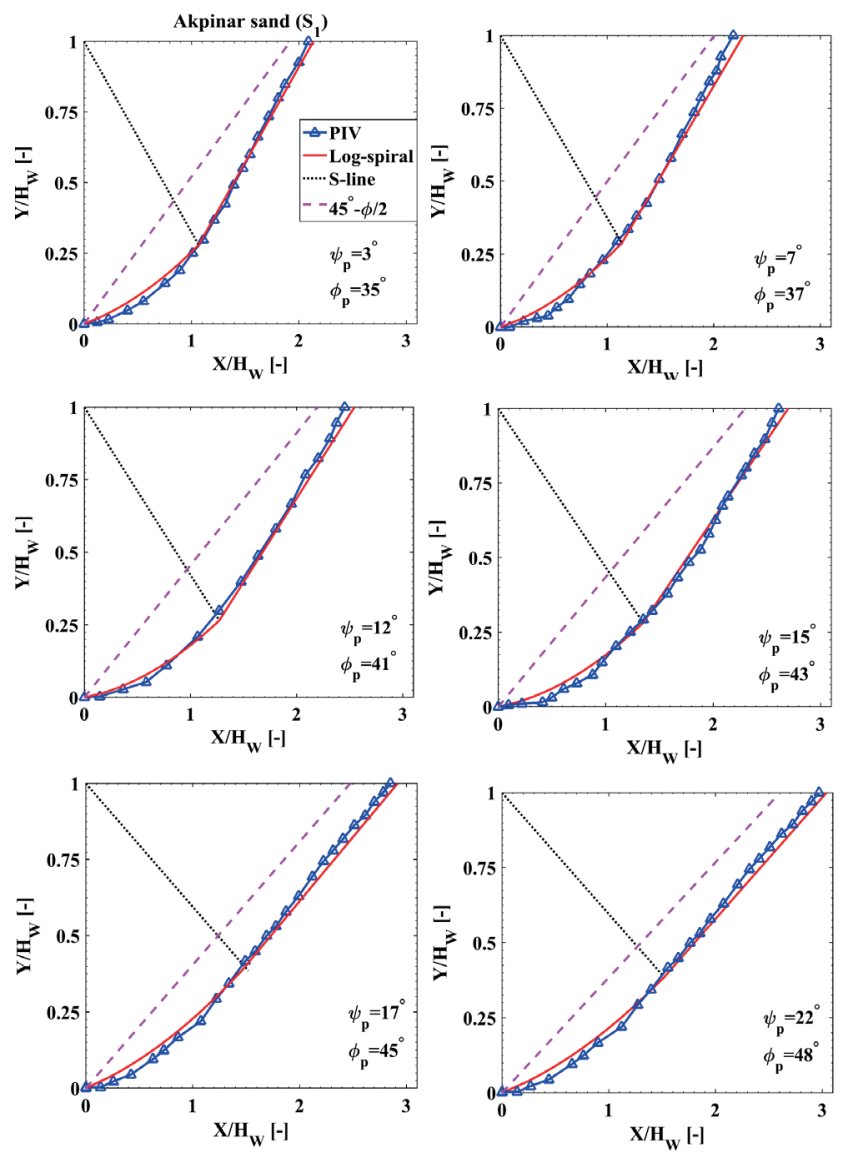

Fig. 7 Fitting experimentally visualized failure surfaces with log-spiral function (for $\mathrm{S}_{1}$ )

Evidently, it is necessary to know the magnitudes of the parameters $\theta$ and $\alpha$ for plotting the linear and curved portions of the predicted failure surfaces. Therefore, this study attempts experimentally to examine the dependence of the necessary unknown fitting parameters (i.e. $\theta$ and $\alpha$ ) on $\phi_{p}{ }^{\prime}$. Experimentally obtained variations of $\theta$ and $\alpha$ are shown in Fig. 9 for both $S_{1}$ and $S_{2}$ sands.
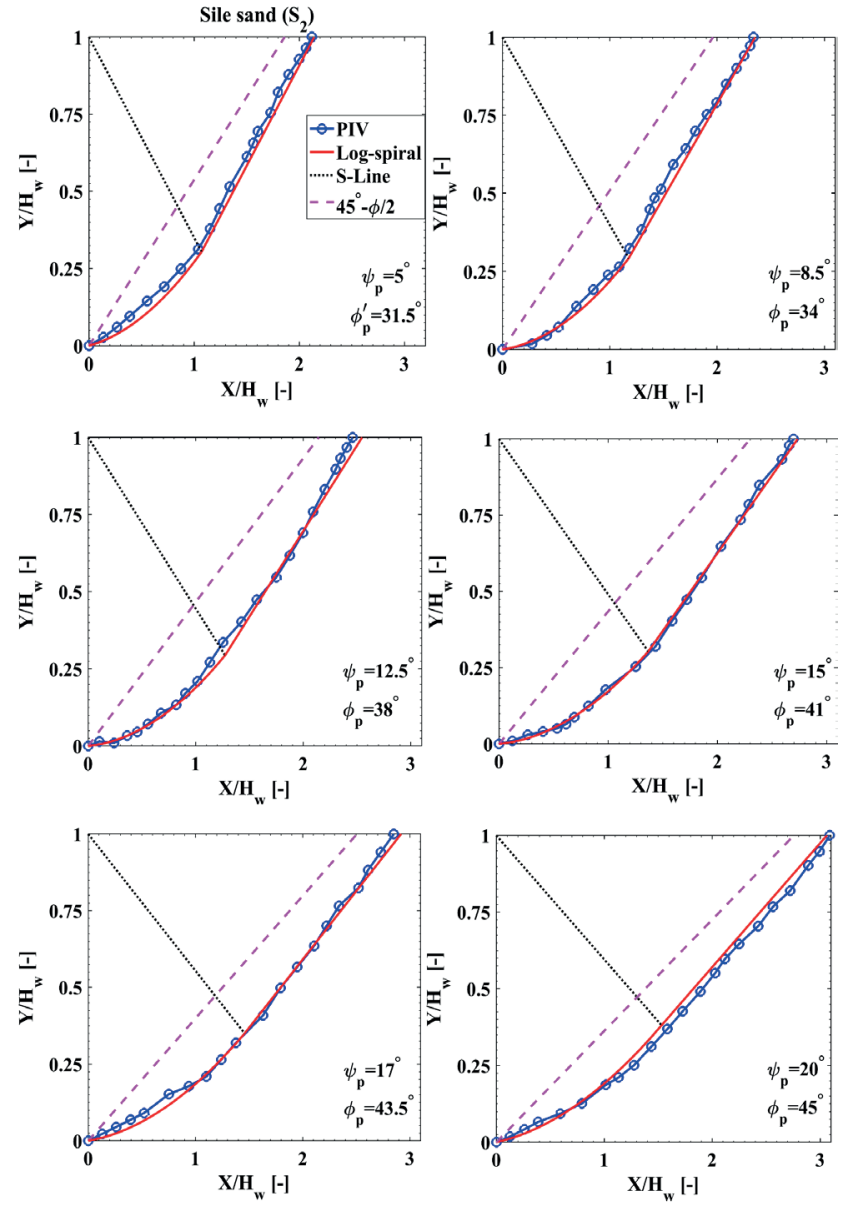

Fig. 8 Fitting experimentally visualized failure surfaces with log-spiral function (for $\mathrm{S}_{2}$ )
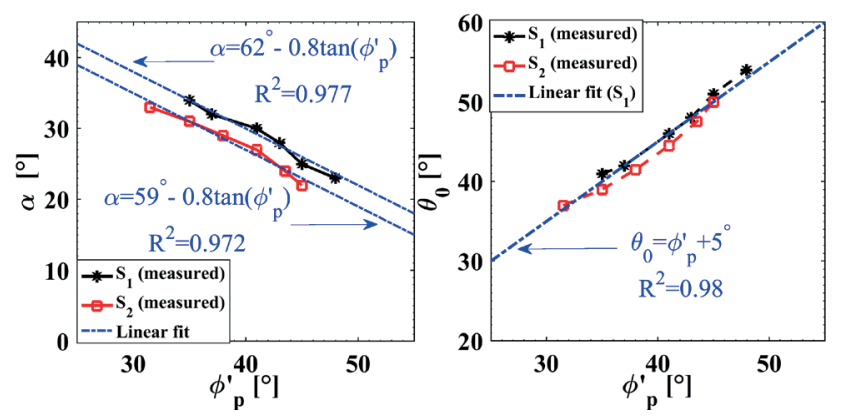

Fig. 9 Variation of fitting parameters with $\phi_{p}{ }^{\prime}$ (for the best fitting logspiral function)

From Fig. 9, it is noticed that the variations of all examined parameters $(\theta$ and $\alpha)$ with $\phi_{p}^{\prime}$ are linear for both sands. In case of $\alpha-\phi_{p}{ }^{\prime}$ relationship, experimentally obtained relat-ionships are inversely linear for both sands (Fig. 9(a)) and are given in Eq. (14) for $\mathrm{S}_{1}$ sand and in Eq. (15) for $\mathrm{S}_{2}$ sand:

$$
\begin{aligned}
& \alpha_{S_{1}}=62^{\circ}-0.8 \phi_{p}{ }^{\prime}, \\
& \alpha_{S_{2}}=59^{\circ}-0.8 \phi_{p}{ }^{\prime} .
\end{aligned}
$$


Noticeable in Eqs. (14) and (15), the slopes of $\alpha-\phi_{p}^{\prime}$ are the same for both soils and their zero-intercepts only slightly differ. The forms of the experimentally obtained $\alpha-\phi_{p}^{\prime}$ relationships are the same as the commonly used $\alpha=45^{\circ}-\phi_{p}^{\prime} / 2$ relationship in literature [2, 3], whereas the values of their zero-intercepts and slope differ.

Additionally, experimentally obtained variations of $\theta_{0}$ with $\phi_{p}{ }^{\prime}$ for both soils are presented in Fig. 9. The results point to a linear relationship as given in Eq. (16).

$\theta_{0}=\phi_{p}{ }^{\prime}+5^{\circ}$

The results provided linear correlations between peak friction angle and the unknown fitting parameters $\left(\theta, \theta_{0}\right.$ and $\alpha$ ). Additionally, $r_{0}$ is also defined as function of $H_{w}$ $\theta_{0}$ and $\alpha$. Thus, the general log-spiral function can be suggested in the new form as:

$r=H_{W} \tan \left(\theta_{0}\right)\left(\frac{\sin (\alpha)}{\sin (\theta)}+\frac{1}{\cos \left(\theta_{0}\right)}\right) e^{\left(\theta \tan \left(f_{p}^{\prime}\right)\right)}$.

The proposed equation is unique, since it only uses peak friction angle as the input parameter to estimate the failure surface geometry under passive state.

\section{Discussion}

As shown in the previous section of this paper, geometrical characteristics of passive failure surfaces are obtained for two different soils for a range of relative densities. The premise of this paper is that the geometrical characteristics of failure surfaces are linked directly to the magnitude of $\psi_{p}$ (failure surface geometry is dependent on density and stress state and because peak dilatancy angle $\left(\psi_{p}\right)$ embodies the combined effects). However, determination of $\psi_{p}$ is not very straightforward in practice. That is why the soil parameter to link to the failure surfaces' shape is chosen as the peak friction angle $\left(\phi_{p}{ }^{\prime}\right)$.

The determination of $\phi_{p}^{\prime}$ is common practice and is done in almost all projects. Moreover, $\phi_{p}^{\prime}$ is a direct function of $\psi_{p}$ as shown in Eq. (1). Obtained results supported the proposition regarding the dependence of failure surface geometries on $\phi_{p}{ }^{\prime}$ and the results are shown in Fig. 9. The necessary geometrical features of a passive failure surface are defined as a function of $\theta$ and $\alpha$, of which both vary linearly with $\phi_{p}^{\prime}$.

Additionally, when the results obtained from $\mathrm{S}_{1}$ and $\mathrm{S}_{2}$ sands are compared, it is noticed that the variations of $\theta$ and $\alpha$ with $\phi_{p}{ }^{\prime}$ are very similar. This suggests a direct dependence of passive failure surface geometry on $\phi_{p}{ }^{\prime}$ which requires further studying. Especially, because both backfill soils used in model tests are poorly graded, tests on a well-graded soil will give valuable information regarding the influence of gradation characteristics on the geometry of failure planes. Another possible influence on passive failure geometry is the mode of wall movement. This study used model tests which involve lateral translation of a rigid wall. However, in problems where the wall rotates or deforms, the resulting passive failure geometry will most likely change.

On the other hand, it is necessary to note that all the mentioned shortcomings also apply to conventional methods of failure surface geometry prediction, such as Coulomb [2] or Rankine [3]. Fig. 7 and Fig. 8 also include comparisons with the conventional passive failure surface predictions. Evidently, linear failure surface predictions are significantly different from the experimentally determined passive failure surfaces. Therefore, the use of new form of log-spiral function (Eq. (17)), for determining passive failure surface geometries for cohesionless backfills, will result in more accurate predictions.

\section{Conclusions}

The classical theories on passive failure planes assume planar surfaces. However, as explained in the introduction section of this paper, the curved nature of failure surfaces is well-known by researchers. However, approaches for mathematically defining the curved forms of passive failure surfaces are still lacking. Several researchers have noticed the suitability of log-spiral function for defining passive failure surfaces, but without linking the geometrical characteristics of the failure surfaces to the mechanical properties of backfill soils [16, 25]. This is attempted in this study through the use of model tests. The mechanical parameter for identifying the failure surface geometry is selected as the peak friction angle since it blends the influences of backfill density and stress state. Model tests are conducted with two different sands at different relative densities corresponding to different peak friction angles. Failure surfaces are determined using Particle Image Velocimetry (PIV) analyses.

Based on the results, it is seen that the passive failure surfaces are non-linear for both sand types and at all density levels. For dense backfills with higher $\phi_{p}^{\prime}$, resulting failure surfaces extend further away from the model wall. Additionally, obtained failure surfaces are fitted with a log-spiral function. It is noticed that log-spiral functions fit the experimentally determined failure surfaces with 
high accuracies. On the other hand, the linear failure surfaces proposed by classical theories depart significantly away from the actual failure surfaces.

When the variations of geometrical characteristics of experimental failure surfaces with $\phi_{p}^{\prime}$ are investigated, it is noticed that the relationships are all linear. Consequently, obtained results suggest that log-spiral method can precisely predict the passive pressure failure surface geometry.

\section{References}

[1] Salgado, R. "The Engineering of Foundations", 1st ed., McGrawHill, Boston, MA, USA, 2008.

[2] Coulomb, C. "Essai sur une application des regles des maximis et minimis a quelues problemes de statique relatifs a larchitecture" (Test on an application of the rules of maximis and minimis to some problems of statics relating to architecture), In: Memoires de mathematique et de physique, Presentes a l'Academie Royale des Sciences, Paris, France, 1776, pp. 343-382. (in French)

[3] Rankine, W. J. M. "II. On the Stability of Loose Earth", Philosophical Transactions, 147(84), pp. 9-27, 1857. https://doi.org/10.1098/rstl.1857.0003

[4] Hansen, J. B. "Earth Pressure Calculation", The Danish Technical Press, Copenhagen, Denmark, 1953.

[5] Narain, J., Saran, S., Nandakumaran, P. "Model Study of Passive Pressure in Sand", Journal of the Soil Mechanics and Foundation Division, 95(4), pp. 969-984, 1969.

[6] Rowe, P. W., Peaker, K. "Passive Earth Pressure Measurements", Géotechnique, 15(1), pp. 57-78, 1965.

https://doi.org/10.1680/geot.1965.15.1.57

[7] Duncan, J. M., Mokwa, R. L. "Passive Earth Pressures: Theories and Tests", Journal of Geotechnical and Geoenvironmental Engineering, 127(3), pp. 248-257, 2002.

https://doi.org/10.1061/(ASCE)1090-0241(2001)127:3(248)

[8] Wilson, P., Elgamal, A. "Large-Scale Passive Earth Pressure Load-Displacement Tests and Numerical Simulation", Journal of Geotechnical and Geoenvironmental Engineering, 136(12), pp. 1634-1643, 2010.

https://doi.org/10.1061/(ASCE)GT.1943-5606.0000386

[9] Tajabadipour, M., Marandi, M. "Effect of rubber tire chips-sand mixtures on performance of geosynthetic reinforced earth walls Effect of Rubber Tire Chips-Sand Mixtures on Performance of Geosynthetic Reinforced Earth Walls", Periodica Polytechnica Civil Engineering, 61(2), pp. 322-334, 2017.

https://doi.org/10.3311/PPci.9539

[10] Chogueur, A., Abdeldjalil, Z., Reiffsteck, P. "Parametric and Comparative Study of a Flexible Retaining Wall", Periodica Polytechnica Civil Engineering, 62(2), pp. 295-307, 2018. https://doi.org/10.3311/PPci.10749

[11] Yu, Q., Chen, X., Dai, Z., Nie, L., Soltanian, M. R. "Numerical Investigation of Stress Distributions in Stope Backfills", Periodica Polytechnica Civil Engineering, 62(2), pp. 533-538, 2018. https://doi.org/10.3311/PPci.11295

[12] Shields, D. H., Tolunay, A. Z. "Passive Pressure Coefficients by Method of Slices", Journal of the Soil Mechanics and Foundations Division, 99(12), pp. 1043-1053, 1973.
Moreover, using the results presented in this study, it is possible to define log-spiral passive failure surfaces using $\phi_{p}{ }^{\prime}$ as the only input parameter.

\section{Acknowledgement}

Authors would like to thank the Scientific and Technological Research Council of Turkey (TUBITAK Project 114M329) for providing financial support.

[13] Benmeddour, D., Mellas, M., Frank, R., Mabrouki, A. "Numerical study of passive and active earth pressures of sands", Computers and Geotechnics, 40, pp. 34-44, 2012. https://doi.org/10.1016/j.compgeo.2011.10.002

[14] Reddy, N. S. C., Dewaikar, D. M., Mohapatra, G. "Computation of Passive Earth Pressure Coefficients for a Horizontal Cohesionless Backfill Using the Method of Slices", International Journal of Advanced Civil Engineering and Architecture Research, 2(1), pp. 32-41, 2013. [online] Available at: http://technical.cloud-journals. com/index.php/IJACEAR/article/view/Tech-131

[15] Guo, N., Zhao, J. "Multiscale insights into classical geomechanics problems", International Journal for Numerical and Analytical Methods in Geomechanics, 40(3), pp. 367-390, 2016.

https://doi.org/10.1002/nag.2406

[16] Patki, M. A., Dewaikar, D. M., Mandal, J. N. "Numerical Evaluation of Passive Earth-Pressure Coefficients under the Effect of Surcharge Loading", International Journal of Geomechanics, 17(3), Article number: 6016024, 2016. https://doi.org/10.1061/(ASCE)GM.1943-5622.0000736

[17] Keshavarz, A., Ebrahimi, M. "Axisymmetric passive lateral earth pressure of retaining walls", KSCE Journal of Civil Engineering, 21(5), pp. 1706-1716, 2017. https://doi.org/10.1007/s12205-016-0502-9

[18] Oberhollenzer, S., Tschuchnigg, F., Schweiger, H. F. "Finite element analyses of slope stability problems using non-associated plasticity", Journal of Rock Mechanics and Geotechnical Engineering, 10(6), pp. 1091-1101, 2018.

https://doi.org/10.1016/j.jrmge.2018.09.002

[19] Tejchman, J., Bauer, E., Tantono, S. F. "Influence of initial density of cohesionless soil on evolution of passive earth pressure", Acta Geotechnica, 2, pp. 53-63, 2007. https://doi.org/10.1007/s11440-007-0022-3

[20] Fang, Y.-S., Ho, Y.-C., Chen, T.-J. "Passive Earth Pressure with Critical State Concept", Journal of Geotechnical and Geoenvironmental Engineering, 128(8), pp. 651-659, 2002. https://doi.org/10.1061/(ASCE)1090-0241(2002)128:8(651)

[21] Shiau, J., Smith, C. "Numerical Analysis of Passive Earth Pressures with Interfaces", presented at III European Conference on Computational Mechanics, Lisbon, Portugal, June, 5-8, 2006. https://doi.org/10.1007\%2F1-4020-5370-3_147

[22] Wilson, P., Elgamal, A. "Large-Scale Passive Earth Pressure Load-Displacement Tests and Numerical Simulation", Journal of Geotechnical and Geoenvironmental Engineering, 136(12), pp. 1634-1643, 2010. https://doi.org/10.1061/(ASCE)GT.1943-5606.0000386 
[23] Kumar, J., Subba Rao, K. S. "Passive pressure coefficients, critical failure surface and its kinematic admissibility", Géotechnique, 47(1), pp. 185-192, 1997. https://doi.org/10.1680/geot.1997.47.1.185

[24] Terzaghi, K. "Theoretical Soil Mechanics", John Wiley \& Sons, New York, NY, USA, 1943. https://doi.org/10.1002/9780470172766

[25] Liu, S., Xia, Y., Liang, L. "A modified logarithmic spiral method for determining passive earth pressure", Journal of Rock Mechanics and Geotechnical Engineering, 10(6), pp. 1171-1182, 2018. https://doi.org/10.1016/j.jrmge.2018.03.011

[26] Xu, S.-Y., Kannangara, K. K. P. M., Taciroglu, E. "Analysis of the stress distribution across a retaining wall backfill", Computers and Geotechnics, 103, pp. 13-25, 2018. https://doi.org/10.1016/j.compgeo.2018.07.001

[27] Bishop, A. "Shear strength parameters for undisturbed and remoulded soil specimens", In: Proceedings of the Roscoe Memorial Symposium, Cambridge, UK, 1971, pp. 3-58.

[28] Bolton, M. D. "The strength and dilatancy of sands", Géotechnique, 36(1), pp. 65-78, 1986 https://doi.org/10.1680/geot.1986.36.1.65

[29] Vaid, Y. P., Sasitharan, S. "The strength and dilatancy of sand", Canadian Geotechnical Journal, 29(3), pp. 522-526, 1992. https://doi.org/10.1139/t92-058

[30] Chakraborty, T., Salgado, R. "Dilatancy and Shear Strength of Sand at Low Confining Pressures", Journal of Geotechnical and Geoenvironmental Engineering, 136(3), pp. 527-532, 2010. https://doi.org/10.1061/(ASCE)GT.1943-5606.0000237

[31] Cinicioglu, O., Abadkon, A. "Dilatancy and Friction Angles Based on In Situ Soil Conditions", Journal of Geotechnical and Geoenvironmental Engineering, 141(4), pp. 1-7, 2015. https://doi.org/10.1061/(ASCE)GT.1943-5606.0001272

[32] Ahmadi, H., Hajialilue-Bonab, M. "Experimental and analytical investigations on bearing capacity of strip footing in reinforced sand backfills and flexible retaining wall", Acta Geotechnica, 7, pp. 357373, 2012.

https://doi.org/10.1007/s11440-012-0165-8

[33] Altunbas, A., Soltanbeigi, B., Cinicioglu, O. "Determination of active failure surface geometry for cohesionless backfills", Geomechanics and Engineering, 12(6), pp. 983-1001, 2017. https://doi.org/10.12989/gae.2017.12.6.983

[34] Moghadam, M. J., Zad, A., Mehrannia, N., Dastaran, N. "Experimental evaluation of mechanically stabilized earth walls with recycled crumb rubbers", Journal of Rock Mechanics and Geotechnical Engineering, 10(5), pp. 947-957, 2018.

https://doi.org/10.1016/j.jrmge.2018.04.012
[35] Soltanbeigi, B., Altunbas, A., Cinicioglu, O. "Influence of dilatancy on shear band characteristics of granular backfills", European Journal of Environmental and Civil Engineering, 2019. https://doi.org/10.1080/19648189.2019.1572542

[36] Kamiloğlu, H. A., Sadoğlu, E. "Experimental and Theoretical Investigation of Short-and Long-Heel Cases of Cantilever Retaining Walls in Active State", International Journal of Geomechanics, 19(5), Article number: 4019023, 2019.

https://doi.org/10.1061/(ASCE)GM.1943-5622.0001389

[37] Schanz, T., Vermeer, P. A. "Angles of friction and dilatancy of sand", Géotechnique, 46(1), pp. 145-151, 1996.

https://doi.org/10.1680/geot.1996.46.1.145

[38] Lade, P. V. "Failure Criterion for Frictional Materials", John Wiley \& Sons, London, UK, 1984.

[39] Hanna, A. "Determination of plane-strain shear strength of sand from the results of triaxial tests", Canadian Geotechnical Journal, 38(6), pp. 1231-1240, 2001. https://doi.org/10.1139/t01-064

[40] Cho, G.-C., Dodds, J., Santamarina, J. C. "Particle Shape Effects on Packing Density, Stiffness, and Strength: Natural and Crushed Sands", Journal of Geotechnical and Geoenvironmental Engineering, 132(5), 2006.

https://doi.org/10.1061/(ASCE)1090-0241(2006)132:5(591)

[41] Tehrani, F. S., Han, F., Salgado, R., Prezzi, M., Tovar, R. D., Castro, A. G. "Effect of surface roughness on the shaft resistance of non-displacement piles embedded in sand", Géotechnique, 66(5), pp. 386400, 2016.

https://doi.org/10.1680/jgeot.15.P.007

[42] Stanier, S. A., Blaber, J., Take, W. A., White, D. J. "Improved imagebased deformation measurement for geotechnical applications", Canadian Geotechnical Journal, 53(5), pp. 727-739, 2016. https://doi.org/10.1139/cgj-2015-0253

[43] Sokoray-Varga, B., Józsa, J. "Particle tracking velocimetry (PTV) and its application to analyse free surface flows in laboratory scale models", Periodica Polytechnica Civil Engineering, 52(2), pp. 63-71, 2008

https://doi.org/10.3311/pp.ci.2008-2.02

[44] Terzaghi, K., Peck, R. B., Mesri, G. "Soil Mechanics in Engineering Practice", 3rd ed., John Wiley \& Sons, New York, NY, USA, 1996.

[45] Gezgin, A. T., Cinicioglu, O. "Consideration of locked-in stresses during backfill preparation", Geomechanics and Engineering, 18(3), pp. 247-258, 2019.

https://doi.org/10.12989/gae.2019.18.3.247 